AUTHOR QUERY FORM

\begin{tabular}{|l|l|l|}
\hline \multicolumn{1}{|c|}{} & Journal: 00 & Please e-mail or fax your responses and any corrections to: \\
$\begin{array}{l}\text { E } \\
\text { ELSEVIER }\end{array}$ & Article Number: 2123 & Fax: +31204852799 \\
\hline
\end{tabular}

Dear Author,

Any queries or remarks that have arisen during the processing of your manuscript are listed below and highlighted by flags in the proof. Please check your proof carefully and mark all corrections at the appropriate place in the proof (e.g., by using on-screen annotation in the PDF file) or compile them in a separate list.

For correction or revision of any artwork, please consult http://www.elsevier.com/artworkinstructions.

Articles in Special Issues: Please ensure that the words 'this issue' are added (in the list and text) to any references to other articles in this Special Issue.

Uncited references: References that occur in the reference list but not in the text - please position each reference in the text or delete it from the list.

Missing references: References listed below were noted in the text but are missing from the reference list - please make the list complete or remove the references from the text.

\begin{tabular}{|l|l|}
\hline $\begin{array}{c}\text { Location in } \\
\text { article }\end{array}$ & Query / remark \\
\hline Please insert your reply or correction at the corresponding line in the proof
\end{tabular}

Electronic file usage

Sometimes we are unable to process the electronic file of your article and/or artwork. If this is the case, we have proceeded by: 


\title{
Resident and bone marrow-derived mesenchymal stem cells in head and neck squamous cell carcinoma
}

\author{
Astrid De Boeck ${ }^{\mathrm{a}}$, Kishan Narine ${ }^{\mathrm{b}}$, Wilfried De Neve ${ }^{\mathrm{c}}$, Marc Mareel ${ }^{\mathrm{a}}$, Marc Bracke ${ }^{\mathrm{a}}$, Olivier De Wever ${ }^{\mathrm{a}, *}$ \\ ${ }^{a}$ Laboratory of Experimental Cancer Research, Department of Radiation Oncology and Experimental Cancer Research, \\ Ghent University Hospital, De Pintelaan 185, B-9000 Gent, Belgium \\ ${ }^{\mathrm{b}}$ Division of Cardiac Surgery, Department of Cardiac Sciences, Libin Cardiovascular Institute of Alberta, University of Calgary, Health Sciences Centre, \\ 3330 Hospital Dr. NW, Calgary, AL, Canada T2N 4N1 \\ ${ }^{\mathrm{C}}$ Department of Radiation Oncology_Ghent University Hospital, De Pintelaan 185, 9000 Gent, Belgium
}

\section{A R T I C L E I N F O}

\section{Article history:}

Received 29 October 2009

Received in revised form 21 January 2010

Accepted 22 January 2010

Available online $\mathrm{xxxx}$

\section{Keywords:}

Stromal cells

Invasion

Angiogenesis

Immunomodulation

Myofibroblast

\begin{abstract}
S U M M A R Y
Head and neck squamous cell carcinoma (HNSCC) is a major healthcare problem worldwide affecting more than half a million patients each year. Despite considerable advances in the treatment of HNSCC, a high rate of recurrences aggravates the clinical situation and disease outcomes have only modestly improved. Recent insights show that cancer is not only a disease of the transformed epithelium but is also influenced and dependent on its stromal environment. In this review we suggest that resident and bone marrow (BM)-derived mesenchymal stem cells (MSCs) are precursors of the stroma associated with HNSCC and contribute to and lymphangiogenesis, modulate the immune system and produce tumor-associated myofibroblasts. In addition, the impact of radiation therapy on the stromal reaction in HNSCC is discussed. Understanding the mechanisms of how MSCs promote invasive growth and metastasis in HNSCC and respond to cancer management strategies is of profound medical importance and will help us to design improved therapeutic protocols.
\end{abstract}

(c) 2010 Published by Elsevier Ltd.

\section{Introduction}

Head and neck squamous cell carcinoma (HNSCC) primarily affects the mucosa of the upper aerodigestive tract, comprising the nasal and paranasal sinuses, nasopharynx, oropharynx, oral cavity, hypopharynx and larynx. The American Cancer Society estimates that approximately 35,720 new cases of HNSCC will have been diagnosed in the United States in 2009. ${ }^{1}$ Worldwide, HNSCC is the sixth most common malignancy with an incidence of 644,000 new cases a year. ${ }^{2}$ Despite considerable advances in the treatment of HNSCC, a high rate of recurrences and distant metastasis aggravates the clinical situation. ${ }^{3}$ Recent insights show that cancer is not only a disease of the transformed epithelium but is also fundamentally influenced by its stromal environment. ${ }^{4}$ Pre-cancerous conditions of HNSCC, such as oral submucous fibrosis, are characterized by accumulation of type I collagen within the subepithelial tissue. ${ }^{5}$ In agreement, molecular classification of HNSCC using patterns of gene expression reveals distinct subtypes and includes a normal epithelium-like subtype and a subtype with high levels of antioxidant enzymes both with better recurrence-free survival data compared to subtypes with an epidermal growth factor receptor (EGFR)-pathway signature or a mesenchymal-enriched subtype. ${ }^{6}$

\footnotetext{
* Corresponding author. Tel.: +32 9 3323008; fax: +32 93324991.

E-mail address: olivier.dewever@ugent.be (O. De Wever).
}

High levels of EGFR expression in squamous cell carcinoma (SCC) correlate with worse clinical outcome, ${ }^{7}$ and decreased response to radiotherapy, as evidenced by increased locoregional recurrence. ${ }^{8}$ Cetuximab is an IgG1 monoclonal antibody that exclusively targets EGFR with high affinity, and inhibits endogenous ligand binding, thereby blocking receptor dimerisation, tyrosine kinase phosphorylation, and signal transduction. ${ }^{9}$ A recent randomized trial showed that cetuximab plus radiotherapy (versus radiotherapy alone) significantly improves locoregional control and 5-years survival without worsening radiotherapy-related toxicity. ${ }^{10}$ The mechanisms by which cancer cells manipulate their local stroma in the mesenchymal-enriched subtype is more a matter of debate compared to the EGFR-pathway subtype. In this review we discuss that resident and bone marrow (BM)-derived mesenchymal stem cells (MSCs) are precursors of the stroma associated with HNSCC. Here, MSCs contribute to blood and lymph angiogenesis, modulate the immune system and produce tumor-associated myofibroblasts. Radiation therapy is a mainstay of curative therapy for HNSCC. Recent advances have focused primarily on fractionation schedules and the use of intensity modulated radiation therapy (IMRT), a form of high-precision radiotherapy that delivers radiation more precisely to the tumor while sparing the surrounding normal tissues. IMRT has greatly improved locoregional tumor control for paranasal sinuses and pharyngolaryngeal carcinoma but had little effect on distant metastasis. ${ }^{11}$ Reports indicate that radiation 
increases local and distant recruitment of MSCs into irradiated tissues. ${ }^{12,13}$ The consequent production of factors derived from MSCs or from differentiated myofibroblasts, known to possess pro-invasive activities, ${ }^{14}$ may contribute to distant metastasis and so neutralize the benefit of locoregional control. Several reports of HNSCC suggest that there are indeed certain circumstances, not yet fully understood, under which radiotherapy favours relapse and metastasis (reviewed in ${ }^{15}$ ). Understanding the molecular biology of cancer progression and management in this regard motivated this detailed analysis of HNSCC-associated MSCs.

\section{Definition and characterization of MSCs}

The concept of MSCs can be traced to the late nineteenth century work of E. Goujon (a.d. 1869), confirmed by A. Baikow (a.d. 1870), who described the osteogenic potential of heterotopic transplants of rabbit BM. ${ }^{16}$ This osteogenic potential of BM was a feature of a specific subgroup of cells, termed the "Colony Forming Unitfibroblasts" (CFU-f), which made up a very small percentage of the total BM cell population. ${ }^{17}$ Subsequent studies demonstrated that these cells could differentiate into various other mesenchymal cell lineages, and they were therefore called MSCs. ${ }^{18}$ The definition and designation of MSCs remains a point of discussion, especially since our knowledge is solely based on the characterization of cultured cells. In this review, the designation "MSCs" refers to tissue culture-adherent stromal cells isolated from a variety of tissues and capable of differentiating into cell lineages of mesenchymal tissues such as adipocytes, osteocytes, chondrocytes and connective tissue cells.

MSCs express a variety of antigens that are also expressed by many other cell types and to date no unique MSC immunophenotyping marker(s) has(ve) been identified. ${ }^{19}$ MSCs express CD73 (ecto-5'-nucleotidase), CD90 (Thy-1) and CD105 (endoglin), but not CD11b, CD14, CD19, CD34, CD45, CD79 $\alpha$ and HLA class II.

Classically, MSCs are plated on tissue-culture substrates in lowglucose $\left(1 \mathrm{~g} \mathrm{~L}^{-1}\right)$ Dulbecco's Modified Eagle's Medium (DMEM), supplemented with $10 \%$ of selected batches of fetal bovine serum (FBS). After several passages, MSCs enter senescence, with changes in morphology and a reduced proliferation and differentiation potential. The pace of senescence is affected by the culture conditions. A culture system which allows dynamic expansion of a high-extension silicone rubber (HESR) substrate with a much lower stiffness $\left(10-20 \times 10^{3} \mathrm{~Pa}\right)$ as compared to tissue-culture substrates $\left(2.78 \times 10^{9} \mathrm{~Pa}\right)^{20}$ reduces contact inhibition and results in longer preservation of the cell phenotype. Moreover, the growth on expandable HESR matrices suppresses expression of $\alpha$-smooth muscle actin (SMA), a functional marker for fibrogenic myofibroblasts, expressed by MSCs on tissue-culture substrates.

\section{MSCs in noncancerous normal and pathological situations}

\section{Embryogenesis of MSCs}

MSCs in the head and neck region possibly have a different origin as compared to the rest of the body. Cranial skeleton and other mesenchymal tissues of head and neck are mainly derived from the neural crest (NC), ${ }^{21}$ except for the occipital and otic (partly) regions of the skull, which are derived from the mesoderm. ${ }^{22}$ Trunk and limb mesenchyme is derived from the mesoderm. ${ }^{23} \mathrm{NC}$ can generate MSCs. Mesoderm can generate mesenchymal tissues without transiting through an MSC intermediate and it is unclear whether MSCs are derived from the mesoderm. ${ }^{24}$ The development of MSCs arises in multiple waves from distinct origins (Fig. 1). ${ }^{24}$ The earliest wave originates in the neuroepithelial and $\hat{\mathrm{NC}}$ cells. An NC gene network regulates EMT (epithelial-to-mesenchymal transition) of neuroectodermal cells at the dorsal aspect of the neural tube and generates the $\mathrm{NC}$, containing highly invasive cells that give rise to MSCs, as well as neurons and glial cells. ${ }^{21,25}$ Later, a wave of MSCs from as yet unidentified sources, possibly mesoderm or NC-derived MSCs, becomes increasingly important. ${ }^{24}$

Besides their role in embryogenesis of mesenchymal tissues, MSCs colocalize with foci of haematopoiesis early in ontogeny suggesting that they support fetal haematopoiesis. MSCs circulate in fetal blood, from at least 7 weeks gestation at the onset of haematopoiesis and disappear from the circulation by the end of the first trimester, before haematopoiesis becomes e्रstablished. ${ }^{26} \wedge$

\section{MSC distribution and funktion in adult tissues,}

BM serves as a reservoir for MSCs, were they represent 0.01$0.001 \%$ of all nucleated cells. ${ }^{27}$ MSCs are also distributed throughout the body. Specifically, MSCs have been isolated from several oral tissues including dental pulp, dental follicle, apical papilla, periodontal ligament and palatine tonsil. ${ }^{28-32}$ MSCs are not found in peripheral blood under normal c्रonditions, ${ }^{33-35}$ but can be derived from granulocyte colony-stimulating factor (G-CSF) mobilised peripheral blood or umbilical cord blood. ${ }^{33}$ The distribution of MSCs throughout the body raised the question whether there exist a common MSC niche. ${ }^{34}$ The derivation from the aorta, vena cava and other vessels points to a perivascular niche. ${ }^{34,36}$ With the use of the markers Stro- 1 and CD146, MSCs are found lining blood vessels in human BM and dental pulp. ${ }^{29}$ Localisation of MSCs to perivascular niches throughout the body gives them easy access to all tissues when needed for tissue repair or remodelling, provided they conserve the invasive characteristics of their progenitors, e.g. NC cells. MSCs can either provide daughter cells that differentiate and then participate in the structural repair of a wound, or can supply secreted factors that support wound repair and modulate the immune system. ${ }^{37}$ After systemic administration, BM MSCs home and engraft in damaged organs such as vascular tissue, myocardium, brain, liver, kidney, lung and skin resulting in morphological and functional improvements (reviewed $i^{38}$ ). During radiotherapy, damage will occur in normal tissues lying in the radiation field. For radiotherapeutic treatment of HNSCC, the salivary glands are one of the tissues at risk. G-CSF-mobilized BM-derived cells specifically homed to radiation-induced damaged salivary glands after radiotherapy and induced-repair processes. ${ }^{39}$

\section{MSCs in HNSCC}

Tumor metastasis involves extensive interactions of the invasive cancer cells with host stromal components. Tumor stroma comprises extracellular matrix (ECM) and a plethora of cells that work in concert such as myofibroblasts, tumor-associated macrophages, mast cells, neutrophils, endothelial cells, and bacteria. ${ }^{40}$ All of them critically influence the process of carcinogenesis and tumor progression. The mechanisms by which cancer cells manipulate their local ecosystem are still a matter of debate. In this review we discuss the hypothesis that resident and BM MSCs are precursors of the stroma associated with HNSCC, thereby promoting invasive tumor growth and distant metastasis. Furthermore, we will address the question whether radiotherapy affect MSC recruitment and differentiation and by inference the surrogate endpoints invasion and metastasis. HNSCC is a significant health problem, with extremely poor outcomes and significant morbidity if patients have a disease recurrence at the locoregional site. After surgical resection, microscopic cancer cells left behind in the wound margins of the surgical resection bed increase the likelihood of local failures. ${ }^{41}$ The immediate postoperative period may be a time of maximum growth stimulus for any residual cancer 


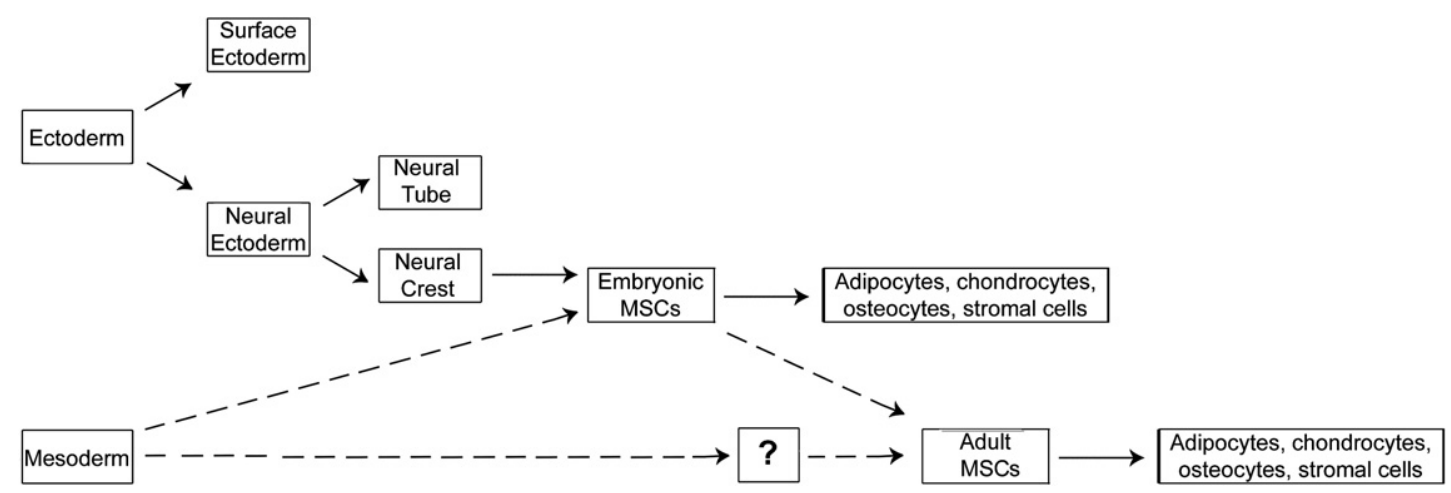

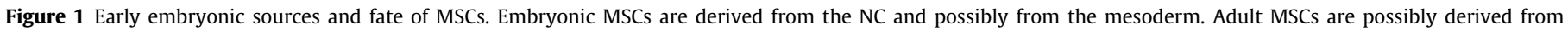
derivatives of the mesoderm or from NC-derived MSCs. Solid arrows indicate the direction of development. Dashed arrows indicate possible directions of development.

(stem) cell. ${ }^{42}$ Furthermore, the process of wound repair after surgical extirpation in the surgical wound involves the recruitment of MSCs and consequent secretion of many factors that stimulate repair $^{37}$ and relapse if residual cancer (stem) cells are present. Postoperative adjuvant radiotherapy may further increase the recruitment of MSCs into the wound site causing a vicious cancer progression cycle. Traditionally, patients with positive margins receive postoperative radiotherapy and/or chemotherapy; however the prognosis for these patients remains poor. Approximately $75 \%$ of patients with positive surgical margins develop local recurrence following radiotherapy according to one study. ${ }^{43}$,

\section{Recruitment of MSCs to HNSCC}

Cytokines and growth factors secreted by tumors recruit resident and distant respondent cells such as MSCs. ${ }^{44,45}$ Intravenously injected green fluorescent protein (GFP)-labelled MSCs in the tail vein of tumor bearing mice are recruited to xenografts derived from several cancer cell lines including UMSCC1 HNSCC cells. ${ }^{12} \mathrm{Al}-$ tered expression of cytokines and growth factors plays a major role in the malignant transformation of many cancers including HNSCC. ${ }^{46}$ Decreasing cytokine levels in serum are associated with response to therapy, while increasing levels are related to HNSCC progression and recurrence. ${ }^{47}$ Over-expression of tumor necrosis factor (TNF)- $\alpha$, vascular endothelial growth factor (VEGF), hepatocyte growth factor (HGF), platelet-derived growth factor (PDGF)$\mathrm{AB}$, transforming growth factor (TGF)- $\beta 1$ and interleukins (ILs), has, been observed in HNSCC cells in vitro as well as in patients' tumor specimens and serum. ${ }^{46,48}$ Among them, PDGF-AB, VEGF, HGF en IL-8 exert strong chemotactic effects on BM MSCs and are possibly involved in MSC recruitment to HNSCC. ${ }^{49}$ Priming of MSCs with pro-inflammatory cytokines like TNF $\alpha$ enhances migration of MSCs in vitro suggesting that the mobilisation and subsequent homing to tumors depend on the systemic and local inflammatory state. ${ }^{49}$ Indeed, a chronic increase in inflammatory mediators in the oral cavity and oropharynx can lead to increased invasion and metastasis. ${ }^{50}$ Furthermore, inflammatory cytokines stimulate specific matrix metalloproteinase (MMP) activity in MSCs assisting passage through the basement membrane during extravasation. ${ }^{51}$

Anti-cancer treatment influences recruitment of MSCs. Irradiated tumors, compared to unirradiated tumors, show an increase in MSC recruitment. ${ }^{13}$ This was demonstrated by bilateral hind leg breast tumor implants: one was left untreated, whereas the other was irradiated before intravenous injection of MSCs. At $48 \mathrm{~h}$ postirradiation, more MSCs were detected in the irradiated than in the unirradiated limbs. In unirradiated tumors, MSCs were more commonly associated with intravascular or perivascular structures, whereas in irradiated tumors, MSCs were present in higher proportions in the tumor parenchyma. MSC migration to irradiated tumors may result from a dynamic interplay in which cancer cells secrete cytokines in response to radiation, leading to chemokine receptor upregulation on MSCs, and ultimately resulting in enhanced migration towards the chemokine ligand-bearing tumor. The consequent production of MSC-derived factors may contribute to relapse and metastasis. In this context it may be interesting to compare immunohistochemically, provided specific markers can be developed, the presence of MSCs and/or terminally differentiated myofibroblasts in HNSCC patients treated or not by IMRT. In a cell culture model we may understand how MSCs react to cancer management protocols including radio-chemotherapy.

\section{MSCs and HNSCC progression}

In vitro and in vivo models have shown that MSCs stimulate invasive growth of solid and haematological tumors. ${ }^{52,53}$ Tumorstroma interactions are important in HNSCC pathogenesis. $^{48,54,55}$ We suggest that MSCs are involved in HNSCC progression by: (i) supporting blood and lymph angiogenesis, (ii) modulating the immune system, and (iii) generating tumor-associated myofibroblasts (Fig. 2).

\section{MSCs support blood and lymph angiogenesis}

Blood and hey components of the metastatic spread of cancer cells. Blood angiogenesis is controlled by angiogenic factors directly produced by cancer cells, as well as by factors from the surrounding stromal tissues. VEGF and IL- 8 are prominent pro-angiogenic factors that are upregulated in HNSCC tumors and associated with aggressive tumor growth and decreased survival. ${ }^{56}$ MSCs can act as precursors of endothelial cells and pericytes and promote angiogenesis. ${ }^{57}$ When treated with VEGF, MSCs acquire an endothelial cell phenotype, with expression of vascular endothelial growth factor receptor (VEGFR)-1, VEGFR-2, vascular endothelial (VE)-cadherin, vascular cell adhesion molecule (VCAM)- 1 and von Willebrand Factor (vWF). ${ }^{58}$ MSCs reside in perivascular niches throughout the body ${ }^{29,34}$ and can engraft within blood vessels at sites of hypoxia, ${ }^{59}$ supporting the contribution of MSCs in blood angiogenesis at hypoxic tumor sites. In addition, paracrine factors of MSCs recruit endothelial cells and smooth muscle cells and stimulate their proliferation. ${ }^{60}$ Local injection of MSC-derived conditioned medium (CM) enhances vascularisation and perfusion in an ischemic hindlimb mouse model. ${ }^{60}$ Tissue hypoxia, as present in tumors, is a major stimulus for vascularisation. Hypoxia stimulates MSCs to a 2-fold increase in secretion of proangiogenic factors like VEGF-A, fibroblast growth factor (FGF)-2, FGF-7, IL-1, IL-6, PDGF, TGF- $\beta$, TNF- $\alpha .{ }^{60-62}$ Hypoxic MSCs show 


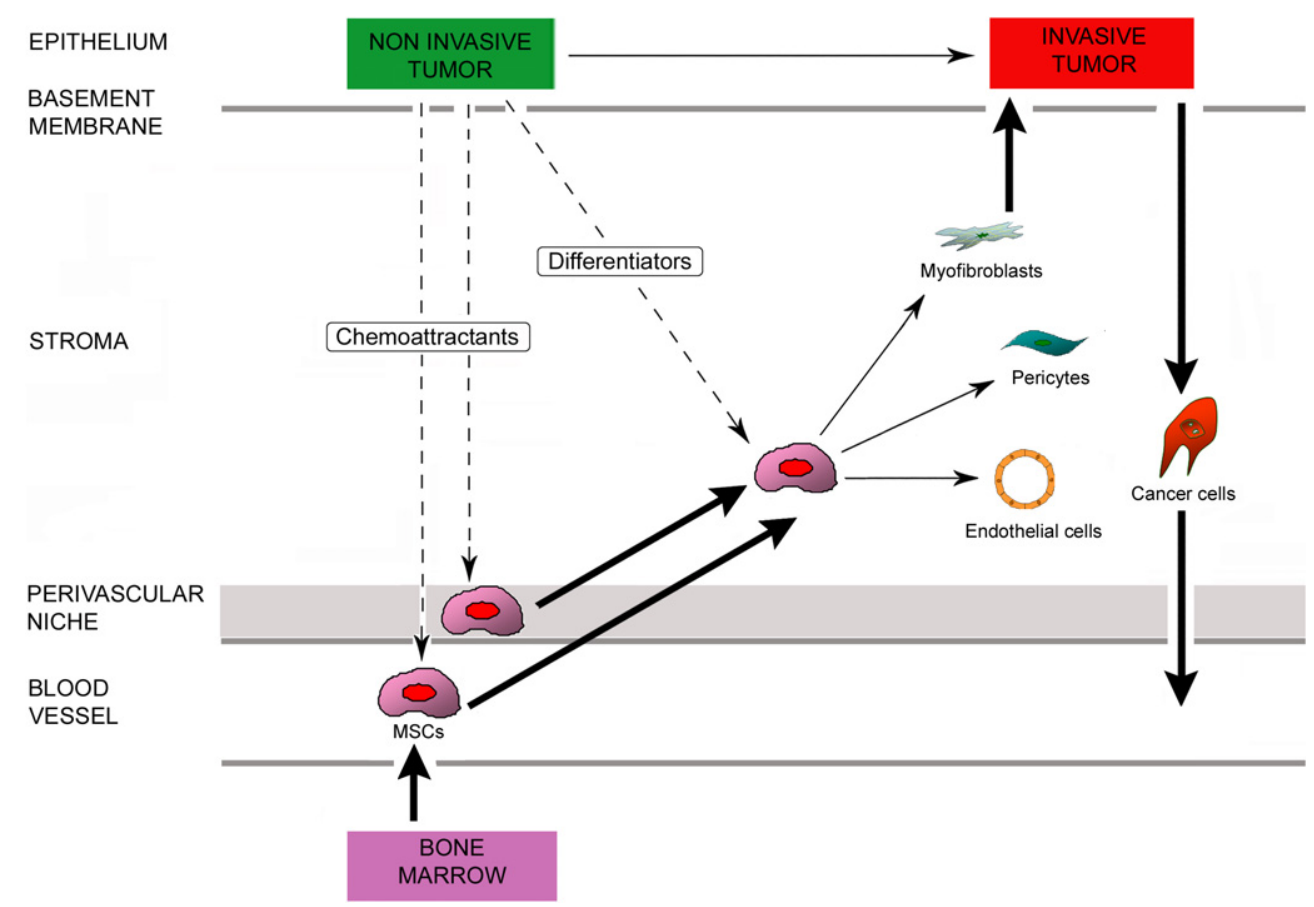

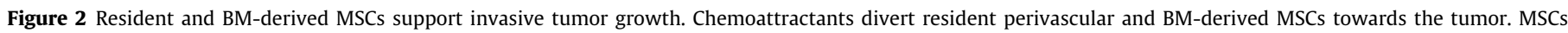

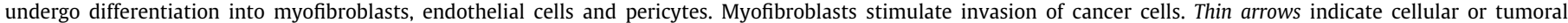
transition. Thick arrows indicate displacement or invasion. Dashed arrows indicate diffusion of soluble factors. Adapted from [110].

improved angiogenic potency compared to naive MSCs when implanted in ischemic hindlimbs. ${ }^{62}$

The involvement of regional lymph nodes is an important indicator of tumor aggressiveness and is a prognostic factor for HNSCC patients. Increased tumor lymph angiogenesis correlates with lymph node metastasis in HNSCC, ${ }^{63}$ but the mechanisms regulating metastatic spread through the lymphatic route remain largely unexplored to date. VEGF-C and VEGF-D are implicated in tumor lymph angiogenesis and lymph node metastases. 64 A direct correlation exist between VEGF-C expression and the presence of lymph node metastases in HNSCC. ${ }^{63,65,66}$ In patients with tongue carcinoma, VEGF-C was associated with primary tumor size, regional lymph node metastasis, distant metastasis and prognosis. Moreover, VEGF-C expression correlated with locoregional recurrence and distant failure. ${ }^{66}$ MSCs have been shown to play a role in lymph angiogenesis and acquire a lymphatic phenotype when exposed to VEGF-C. ${ }^{67}$ Migratory activity of MSCs towards VEGF-C in vitro suggests that VEGF-C may recruit circulating MSCs.

The identification of soluble cancer or stromal cell-derived mediators which stimulate both blood and lymph angiogenesis can reveal targets by which to interrupt tumor angiogenesis which would, in turn, limit the growth and metastatic potential of solid cancers such as HNSCC.

\section{MSCs modulate the immune system}

HNSCC develop molecular strategies to escape efficient antitumor immune responses. ${ }^{68,69}$ HNSCC are infiltrated primary with T cells and dendritic cells (DC), but also with B cells, natural killer (NK) cells, macrophages and eosinophils. Impaired function of $\mathrm{T}$ cells and DC is observed in HNSCC. ${ }^{68}$ MSCs exert local immunosuppressive effects, implicating that engraftment of MSCs in HNSCC creates an immunosuppressive environment. Djouad et al. ${ }^{70}$ demonstrated that MSCs prevented the rejection of allogenic tumor cells in immunocompetent mice. MSCs infused systemically or adjacent to subcutaneously implanted B16 melanoma cells re- sulted in enhanced tumor formation, whereas melanoma cells injected alone were eliminated by the host immune system, suggesting a facilitatory, role of MSCs on allogenic tumor formation. MSCs affect the proliferation and function of immune cells including T cells, DC, NK cells, B lymphocytes and macrophages (reviewed $i^{71}$ ). In vivo and in vitro evidence suggest that the proliferation of stimulated $\mathrm{T}$ cells is inhibited by MSCs without immunological restriction; similar suppressive effects being observed under autologous and allogenic conditions. ${ }^{72}$ This suppression of $\mathrm{T}$ cells affects antigen specific proliferation, expression of activation markers, cytotoxic T cell (CTL) formation and interferon (IFN)- $\gamma$ and IL-4 production. ${ }^{73,74}$ MSCs also induce T cell anergy, an observation supported by their lack of co-stimulatory molecules (B7-1 and B7-2) and the restoration of proliferation following MSCs removal. ${ }^{73,75,76}$ In addition, MSCs modulate the effects of CTLs and suppress CD8 + CTLs, but not activated CD8 + CTLs cells, suggesting a possible inhibition of lymphocyte proliferation with reduced overall CTLs cytolytic response rather than inhibiting cytolysis itself. ${ }^{77,78}$ Both human and mice MSCs inhibit the proliferation of $\mathrm{B}$ cells stimulated by CD40L and cytokines. ${ }^{79,80}$ Furthermore, human MSCs inhibit the differentiation, chemotactic behaviour and antibody secretion of B cells. ${ }^{80}{ }_{\wedge}$

MSCS are a source of HNSCC-associated myofibroblasts

Myofibroblasts are abundantly present in the stroma of developing tumors and drive invasive tumor growth by providing a suitable environment. ${ }^{81,82}$ There is ample evidence for the pro-invasive growth activity of tumor-associated myofibroblasts (recently reviewed in ${ }^{14}$ ), and there is no evidence to suggest that there is a different behaviour of tumor-associated myofibroblasts between HNSCC and other tumors. Myofibroblasts are large spindle-shaped cells with indented nuclei, $\alpha$-SMA containing stress fibers and well-developed cell-matrix interactions (fibronexus). Characterization of stromal myofibroblasts is based on a combination of positive markers such as $\alpha$-SMA, $\gamma$-SMA, desmin, vimentin, prolyl-4 
Table 1

Efferent signals leading to the upregulation of myofibroblast markers and pro-invasive molecules in MSCs.

\begin{tabular}{|c|c|c|c|c|}
\hline Efferent signal & & Myofibroblast marker & Pro-invasive molecule & Reference \\
\hline \multicolumn{5}{|l|}{ Single agent } \\
\hline & 1-Oleol-LPA & $\alpha-S M A$ & SDF-1 & 106 \\
\hline & 5-Azacytidine & $\alpha$-SMA; desmin; FSP & & 92 \\
\hline & PDGF-AA & $\alpha$-SMA & & 107 \\
\hline & TGF- $\beta 1$ & $\alpha$-SMA; calponin; SM22 $\alpha$ & SDF-1 & 106 \\
\hline & TGF- $\beta 3$; D-erythro-SPC & $\alpha$-SMA; calponin; SM $22 \alpha$ & & 108 \\
\hline \multicolumn{5}{|l|}{ CCCM } \\
\hline & MDA-MB-231; PANC-1; U87 & $\alpha$-SMA; desmin; FSP & SDF-1 & 92 \\
\hline & OVCAR-3; ascites ovary tumor & $\alpha$-SMA & SDF-1 & 106 \\
\hline & SK-OV-3 & $\alpha$-SMA; desmin; FAP; FSP & FAP; IL-6; TGF- $\beta 1$; TNC; TSP1; VEGF & 52 \\
\hline \multicolumn{5}{|l|}{ Coculture } \\
\hline & НCT115; НТ29 & $\alpha$-SMA; calponin & & 109 \\
\hline
\end{tabular}

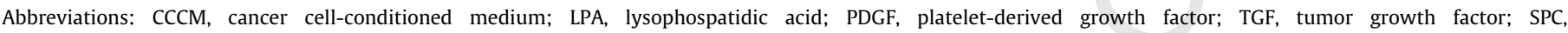

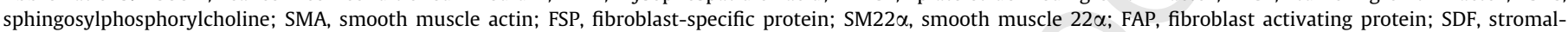
derived factor; TNC, tenascin-C; TSP1, thrombospondin-1; IL, interleukin; VEGF, vascular endothelial growth factor.

hydroxylase $(\mathrm{P} 4 \mathrm{H})$ and negative markers such as cytokeratin, CD31, CD34 and smoothelin. ${ }^{14}$ Stromal myofibroblasts produce ECM components, ECM remodelling enzymes, growth factors, cytokines and chemokines in order to create an invasive growth promoting ecosystem. ${ }^{14}$

Immunohistochemical analysis of $\alpha$-SMA reveals that myofibroblasts are abundantly present in the stroma of HNSCC. ${ }^{54,83-85}$ iTRAQ (a non-gel based technique using isotopes to identify and quantify proteins from different sources in one single experiment) multidimensional liquid chromatography and tandem mass spectrometry revealed the myofibroblast-associated S100-A11 protein calgizarrin as a novel HNSCC biomarker. ${ }^{86}$ Myofibroblast appearcell carcinoma of the oral cavity. ${ }^{81}$ Abundant presence of myofibrofeatures of HNSCC including lymph node metastasis, disease stage and regional recurrence. ${ }^{54,83}$ Understanding the origin and molecular events for the generation of tumor-associated myofibroblasts is still a matter of debate. Tumor-associated myofibroblasts are thought to arise from several mobilised cell types ${ }^{87}$ including migratory neighbours such as tissue-resident MSCs or tissue-resident fibroblasts, and distant invaders such as $\widehat{B M}$-derived MSCs. ${ }^{44,45,88}$ Myofibroblast differentiation is regulated by growth factors, mainly of the TGF- $\beta$ family, ${ }^{89}$ which are secreted abundantly by HNSCC. ${ }^{82,90}$ Interestingly, irradiation generates reactive oxygen species causing oxidation of specific amino acids in the latent TGF- $\beta$ complex and release of its active form. ${ }^{91}$ MSCs exposed to cancer cell-conditioned medium (CCCM), ascites from ovarian cancer patients or soluble cancer cell-derived factors like TGF- $\beta$ or after long-term coculture with cancer cells, acquire a myofibroblast phenotype, characterized by an increased $\alpha$-SMA expression and ECM, protease, and growth factor production (Table 1). These data put forward MSCs as myofibroblast precursors in the stroma sion profiling reveals similarities between CCCM-exposed MSCs and stromal myofibroblasts. ${ }^{92,93}$ The fact that myofibroblasts share surface antigens and functions with MSCs suggest they may originate from the BM. ${ }^{94} \mathrm{BM}$-derived MSC's contribute to $25 \%$ of the total myofibroblast population in the tumor stroma in a mouse model of pancreatic insulinoma ${ }^{44}$ and in a subcutaneous pancreatic xenograft tumor. ${ }^{45}$ Furthermore, these BM-derived MSC-derived myofibroblasts actively participate in the production of TGF- $\beta 1$ derived from several oral squamous cell carcinoma cell lines (OSCC) induces myofibroblast differentiation of primary fibroblasts. Fibrosis in metastatic lymph nodes is a factor of worse prognosis in cancer of the oral cavity. ${ }^{35}$ Several paracrine factors produced by MSCs may be impîicated in HNSCC progression. The ance increases with increasing tumor invasiveness in squamous blasts in the stroma is associated with several clinicopathological of several solid cancers including HNSCC. Moreover, gene expresmatrix proteins, such as collagen type I, in xenograft tumors. ${ }^{44}$
c-Met receptor tyrosine kinase is a potential therapeutic target for HNSCC since scatter factor (SF)/HGF, secreted by stromal HNSCC cells, stimulates invasive growth and angiogenesis. ${ }^{95,96}$ Galectin-1 is significantly overexpressed in the tumor-associated stroma as well as in the invasion front during early oral carcinogenesis and associate with worse disease-free survival. ${ }^{97}$ Stromal-derived factor (SDF)-1 $\alpha$, frequently detected in secretomes of MSCs, ${ }^{98}$ promotes invasion of HNSCC by activating Nuclear Factor- $\mathrm{kB} .{ }^{99}$ Furthermore, gene expression profiles identify activation of Nuclear Factor- $\kappa B$ as characteristic of high-risk HNSCC. ${ }^{100}$ Activation of toll-like receptor 4 signalling in HNSCC cells promotes tumor development ${ }^{101}$ and this activation may be mediated by the tumor-associated stromal cell-derived ECM protein tenascin-C (TNC) ${ }^{102}$ Coculture of primary and metastatic HNSCC cells with fibroblasts derived from human gingiva causes increases in expression of cytokines which are involved in HNSCC cell invasion. ${ }^{48}$ Fibroblast-derived membrane type 1 (MT1)-MMP promote HNSCC cancer cell invasion in cell culture and tumor growth in xenograft models. ${ }^{103}$ The so called isolated fibroblast populations in these studies are likely to be multipotent MSCs, since MSCs can be isolated from a variety of oral tissues by explant culture, as used in these studies. ${ }^{104}$

\section{Conclusions and perspectives}

Understanding the mechanisms of how supporting host cells composing the tumor ecosystem promote invasive growth and metastasis and react to cancer management strategies is profoundly important. Given the role of MSCs in wound repair ${ }^{37}$ and their emerging use as therapeutic agents, ${ }^{105}$ we propose that MSCs are a critical, manipulable component in pre-cancerous conditions such as oral submucous fibrosis ${ }^{5}$ and in the tumor ecosystem of HNSCC. Understanding the role of MSCs within pre-cancerous and cancerous conditions will be extremely valuable. What we lack are methods to specifically mark and trace the lineage of resident MSCs. Such methods, when available, will help us to determine the extent to which MSCs act as stem cells or as sources of secreted factors, as well as to identify distinct functional subpopulations.

\section{Conflicts of Interest Statement}

None declared.

\section{Acknowledgments}

This work was supported by Fund for Scientific Research-Flanders (Brussels, Belgium). A. De Boeck is a doctoral researcher and O. De Wever is a post-doctoral researcher. 


\section{References}

1. Jemal A, Siegel R, Ward E, Hao Y, Xu J, Thun MJ. Cancer statistics, 2009. CA Cancer J Clin 2009;59(4):225-49.

2. Parkin DM, Bray F, Ferlay J, Pisani P. Global cancer statistics, 2002. CA Cancer J Clin 2005;55(2):74-108.

3. Haddad RI, Shin DM. Recent advances in head and neck cancer. N Engl J Med 2008;359(11):1143-54.

4. Weber F, Xu YM, Zhang L, et al. Microenvironmental genomic alterations and clinicopathological behavior in head and neck squamous cell carcinoma. JAMA 2007;297(2):187-95

5. Teh MT, Tilakaratne WM, Chaplin T, et al. Fingerprinting genomic instability in oral submucous fibrosis. J Oral Pathol Med 2008;37(7):430-6.

6. Chung CH, Parker JS, Karaca G, et al. Molecular classification of head and neck squamous cell carcinomas using patterns of gene expression. Cancer Cell 2004;5(5):489-500.

7. He YK, Zeng Q Drenning SD, et al. Inhibition of human squamous cell carcinoma growth in vivo by epidermal growth factor receptor antisense RNA transcribed from the U6 promoter. J Natl Cancer Inst 1998;90(14):1080-7.

8. Ang KK, Berkey BA, Tu XY, et al. Impact of epidermal growth factor receptor expression on survival and pattern of relapse in patients with advanced head and neck carcinoma. Cancer Res 2002;62(24):7350-6.

9. Li S, Schmitz KR, Jeffrey PD, Wiltzius JJ, Kussie P, Ferguson KM. Structural basis for inhibition of the epidermal growth factor receptor by cetuximab. Cancer Cell 2005;7(4):301-11.

10. Bonner JA, Harari PM, Giralt J, et al. Radiotherapy plus cetuximab for locoregionally advanced head and neck cancer: 5-year survival data from a phase 3 randomised trial, and relation between cetuximab-induced rash and survival. Lancet Oncol in press;11(1):21-8 [doi:10.1016/S1470 2045(09)70311-0

11. Gregoire V, De Neve W, Eisbruch A, Lee N, Van den Weyngaert D, Van Gestel D. Intensity-modulated radiation therapy for head and neck carcinoma. Oncologist 2007;12(5):555-64.

12. Zielske SP, Livant DL, Lawrence TS. Radiation increases invasion of genemodified mesenchymal stem cells into tumors. Int J Radiat Oncol Biol Phys 2009;75(3):843-53.

13. Klopp AH, Spaeth EL, Dembinski JL, et al. Tumor irradiation increases the recruitment of circulating mesenchymal stem cells into the tumor microenvironment. Cancer Res 2007;67(24):11687-95.

14. De Wever O, Demetter P, Mareel M, Bracke M. Stromal myofibroblasts are drivers of invasive cancer growth. Int J Cancer 2008;123(10):2229-38.

15. Madani I, De Neve W, Mareel M. Does ionizing radiation stimulate cancer invasion and metastasis? Bull Cancer 2008;95(3):292-300.

16. Dennis JE, Caplan AI. Bone marrow mesenchymal stem cells. In: Sell S, editor. Stem cells handbook. Totowa: Humana Press; 2004. p. 107-18.

17. Friedenstein AJ. Determined and inducible osteogenic precursor cells. In: Katherine Elliott DWF, editor. Ciba foundation symposium 11 - hard tissue growth, repair and remineralization; 1973. p. 169-85.

18. Caplan AI. Mesenchymal stem cells. J Orthop Res 1991:9(5):641-50.

19. Dominici M, Blanc KL, Mueller I, et al. Minimal criteria for defining multipotent mesenchymal stromal cells. The international society for cellular therapy position statement. Cytotherapy 2006;8(4):315-7.

20. Majd H, Wipff P-J, Buscemi L, et al. A novel method of dynamic culture surface expansion improves mesenchymal stem cell proliferation and phenotype. Stem Cells 2009;27(1):200-9.

21. Le Douarin NM, Creuzet S, Couly G, Dupin E. Neural crest cell plasticity and its limits. Development 2004;131(19):4637-50

22. Couly GF, Coltey PM, Le Douarin NM. The triple origin of skull in higher vertebrates: a study in quail-chick chimeras. Development 1993;117(2):409-29.

23. Young HE, Black Jr AC. Adult stem cells. Anat Rec A Discov Mol Cell Evol Biol 2004:276(1):75-102

24. Takashima Y, Era T, Nakao K, et al. Neuroepithelial cells supply an initial transient wave of MSC differentiation. Cell 2007;129(7):1377-88.

25. Nikitina N, Sauka-Spengler T, Bronner-Fraser M. Dissecting early regulatory relationships in the lamprey neural crest gene network. Proc Natl Acad Sci USA 2008;105(51):20083-8.

26. Mendes SC, Robin C, Dzierzak E. Mesenchymal progenitor cells localize within hematopoietic sites throughout ontogeny. Development 2005;132(5):1127-36.

27. Pittenger MF, Mackay AM, Beck SC, et al. Multilineage potential of adult human mesenchymal stem cells. Science 1999;284(5411):143-7.

28. Lindroos B, Mäenpää K, Ylikomi T, Oja H, Suuronen R, Miettinen S. Characterisation of human dental stem cells and buccal mucosa fibroblasts. Biochem Biophys Res Commun 2008;368(2):329-35.

29. Shi S, Gronthos S. Perivascular niche of postnatal mesenchymal stem cells in human bone marrow and dental pulp. J Bone Miner Res 2003;18(4):696-704.

30. Pierdomenico L, Bonsi L, Calvitti M, et al. Multipotent mesenchymal stem cells with immunosuppressive activity can be easily isolated from dental pulp. Transplantation 2005;80(6):836-42.

31. Janjanin S, Djouad F, Shanti RM, et al. Human palatine tonsil: a new potential tissue source of multipotent mesenchymal progenitor cells. Arthritis Res Ther 2008;10(4):R83

32. Sonoyama W, Liu Y, Yamaza T, et al. Characterization of the apical papilla and its residing stem cells from human immature permanent teeth: a pilot study. $J$ Endod 2008;34(2):166-71.
33. Tondreau T, Meuleman N, Delforge A, et al. Mesenchymal stem cells derived from CD133-positive cells in mobilized peripheral blood and cord blood: proliferation, Oct4 expression, and plasticity. Stem Cells 2005;23(8):1105-12.

34. Meirelles LDS, Chagastelles PC, Nardi NB. Mesenchymal stem cells reside in virtually all post-natal organs and tissues. J Cell Sci 2006;119(11):2204-13.

35. Lehn CN, Rapoport A. The desmoplastic lymph node reaction as a prognostic factor of cancer of the tongue and floor of the mouth. Sao Paulo Med 1994;112(3):591-6.

36. Crisan M, Yap S, Casteilla L, et al. A perivascular origin for mesenchymal stem cells in multiple human organs. Cell Stem Cell 2008;3(3):301-13.

37. Stappenbeck TS, Miyoshi H. The role of stromal stem cells in tissue regeneration and wound repair. Science 2009;324(5935):1666-9.

38. Chamberlain G, Fox J, Ashton B, Middleton J. Concise review: mesenchymal stem cells: their phenotype, differentiation capacity, immunological features, and potential for homing. Stem cells 2007;25(11):2739-49.

39. Lombaert IMA, Wierenga PK, Kok T, Kampinga HH, deHaan G, Coppes RP. Mobilization of bone marrow stem cells by granulocyte colony-stimulating factor ameliorates radiation-induced damage to salivary glands. Clin Cancer Res 2006;12(6):1804-12.

40. Joyce JA, Pollard JW. Microenvironmental regulation of metastasis. Nat Rev Cancer 2009;9(4):239-52.

41. Brennan JA, Mao L, Hruban RH, et al. Molecular assessment of histopathological staging in squamous-cell carcinoma of the head and neck. $N$ Engl J Med 1995;332(7):429-35.

42. Ragaz J. Comments on kinetics and biology of the residual cancer, and on relevant therapeutic strategies based on these phenomena. Prog Clin Biol Res 1990;354B: 117-39.

43. Jones AS, Hanafi ZB, Nadapalan V, Roland NJ, Kinsella A, Helliwell TR. Do positive resection margins after ablative surgery for head and neck cance adversely affect prognosis? A study of 352 patients with recurrent carcinoma following radiotherapy treated by salvage surgery. $\mathrm{Br} J$ Cancer 1996;74(1):128-32.

44. Direkze NC, Hodivala-Dilke K, Jeffery R, et al. Bone marrow contribution to tumor-associated myofibroblasts and fibroblasts. Cancer Res 2004;64(23):8492-5.

45. Ishii G, Sangai T, Oda T, et al. Bone-marrow-derived myofibroblasts contribute to the cancer-induced stromal reaction. Biochem Biophys Res Commun 2003;309(1):232-40.

46. Pries R, Nitsch S, Wollenberg B. Role of cytokines in head and neck squamous cell carcinoma. Expert Rev Anticancer Ther 2006;6(9):1195-203.

47. Allen C, Duffy S, Teknos T, et al. Nuclear factor-kB-related serum factors as longitudinal biomarkers of response and survival in advanced oropharyngea carcinoma. Clin Cancer Res 2007;13(11):3182-90.

48. Koontongkaew S, Amornphimoltham P, Yapong B. Tumor-stroma interactions influence cytokine expression and matrix metalloproteinase activities in paired primary and metastatic head and neck cancer cells. Cell Biol In 2009;33(2):165-73.

49. Ponte AL, Marais E, Gallay N, et al. The in vitro migration capacity of human bone marrow mesenchymal stem cells: comparison of chemokine and growth factor chemotactic activities. Stem cells 2007;25(7):1737-45.

50. Wang F, Arun P, Friedman J, Chen Z, Van Waes C. Current and potential inflammation targeted therapies in head and neck cancer. Curr Opin Pharmaco 2009;9(4):389-95.

51. Ries C, Egea V, Karow M, Kolb H, Jochum M, Neth P. MMP-2, MTI-MMP, and TMP-2 are essential for the invasive capacity of human mesenchymal stem cells: differential regulation by inflammatory cytokines. Blood 2007;109(9):4055-63.

52. Spaeth EL, Dembinski JL, Sasser AK, et al. Mesenchymal stem cell transition to tumor-associated fibroblasts contributes to fibrovascular network expansion and tumor progression. PloS One 2009;4(4):e4992.

53. Karnoub AE, Dash AB, Vo AP, et al. Mesenchymal stem cells within tumour stroma promote breast cancer metastasis. Nature 2007:449(7162):557-63.

54. Kellermann MG, Sobral LM, da Silva SD, et al. Mutual paracrine effects of ora squamous cell carcinoma cells and normal oral fibroblasts: induction of fibroblast to myofibroblast transdifferentiation and modulation of tumor cel proliferation. Oral Oncol 2008;44(5):509-17.

55. Nielsen JD, Moeslund M, Wandall HH, Dabelsteen S. Influences of tumo stroma on the malignant phenotype. I Oral Pathol Med 2008;37(7):412-6.

56. Eisma RJ, Spiro JD, Kreutzer DL. Role of angiogenic factors: coexpression of interleukin-8 and vascular endothelial growth factor in patients with head and neck squamous carcinoma. Laryngoscope 1999;109(5):687-93.

57. Lozito TP, Kuo CK, Taboas JM, Tuan RS. Human mesenchymal stem cells express vascular cell phenotypes upon interaction with endothelial cell matrix. J Cell Biochem 2009;107(4):714-22.

58. Oswald J, Boxberger S, Jørgensen B, et al. Mesenchymal stem cells can be differentiated into endothelial cells in vitro. Stem cells 2004;22(3):377-84.

59. Hamou C, Callaghan MJ, Thangarajah H, et al. Mesenchymal stem cells can participate in ischemic neovascularization. Plast Reconstr Surg 2009;123(2 ):45S-55S.

60. Kinnaird T, Stabile E, Burnett MS, et al. Marrow-derived stromal cells express genes encoding a broad spectrum of arteriogenic cytokines and promote in vitro and in vivo arteriogenesis through paracrine mechanisms. Circ Res 2004;94(5):678-85.

61. Potier E, Ferreira E, Andriamanalijaona R, et al. Hypoxia affects mesenchyma stromal cell osteogenic differentiation and angiogenic factor expression. Bone 2007;40(4):1078-87. 
62. Li T-S, Hamano K, Suzuki K, Ito H, Zempo N, Matsuzaki M. Improved angiogenic potency by implantation of ex vivo hypoxia prestimulated bone marrow cells in rats. Am J Physiol Heart Circ Physiol 2002;283(2):H468-73.

63. Beasley NJP, Prevo R, Banerji S, et al. Intratumoral lymphangiogenesis and lymph node metastasis in head and neck cancer. Cancer Res 2002;62(5):1315-20.

64. Stacker SA, Achen MG, Jussila L, Baldwin ME, Alitalo K. Lymphangiogenesis and cancer metastasis. Nat Rev Cancer 2002;2(8):573-83.

65. Kishimoto K, Sasaki A, Yoshihama Y, Mese H, Tsukamoto G, Matsumura T. Expression of vascular endothelial growth factor-C predicts regional lymph node metastasis in early oral squamous cell carcinoma. Oral Oncol 2003;39(4):391-6.

66. Tanigaki Y, Nagashima Y, Kitamura Y, Matsuda H, Mikami Y, Tsukuda M. The expression of vascular endothelial growth factor-A and $-C$, and receptors 1 and 3: correlation with lymph node metastasis and prognosis in tongue squamous cell carcinoma. Int J Mol Med 2004;14(3):389-95.

67. Conrad C, Niess H, Huss R, et al. Multipotent mesenchymal stem cells acquire a lymphendothelial phenotype and enhance lymphatic regeneration in vivo. Circulation 2009;119(2):281-9.

68. Whiteside TL. Immunobiology of head and neck cancer. Cancer Metastasis Rev 2005;24(1):95-105.

69. Jewett A, Head C, Cacalano NA. Emerging mechanisms of immunosuppression in oral cancers. J Dent Res. 2006;85(12):1061-73.

70. Djouad F, Plence P, Bony C, et al. Immunosuppressive effect of mesenchymal stem cells favors tumor growth in allogeneic animals. Blood 2003;102(10):3837-44.

71. Rasmusson I. Immune modulation by mesenchymal stem cells. Exp Cell Res 2006;312(12):2169-79.

72. Le Blanc K, Tammik L, Sundberg B, Haynesworth SE, Ringden O. Mesenchymal stem cells inhibit and stimulate mixed lymphocyte cultures and mitogenic responses independently of the major histocompatibility complex. Scand J Immunol 2003;57(1):11-20.

73. Krampera M, Glennie S, Dyson J, et al. Bone marrow mesenchymal stem cells inhibit the response of naive and memory antigen-specific $T$ cells to their cognate peptide. Blood 2003;101(9):3722-9.

74. Aggarwal S, Pittenger MF. Human mesenchymal stem cells modulate allogeneic immune cell responses. Blood 2005;105(4):1815-22.

75. Di Nicola M, Carlo-Stella C, Magni M, et al. Human bone marrow stromal cells suppress T-lymphocyte proliferation induced by cellular or nonspecific mitogenic stimuli. Blood 2002;99(10):3838-43.

76. Glennie S, Soeiro I, Dyson PJ, Lam EW-F, Dazzi F. Bone marrow mesenchymal stem cells induce division arrest anergy of activated $\mathrm{T}$ cells. Blood 2005;105(7):2821-7.

77. Rasmusson I, Ringden O, Sundberg B, Le Blanc K. Mesenchymal stem cells inhibit the formation of cytotoxic T lymphocytes, but not activated cytotoxic T lymphocytes or natural killer cells. Transplantation 2003;76(8):1208-13.

78. Karlsson H, Samarasinghe S, Ball LM, et al. Mesenchymal stem cells exert differential effects on alloantigen and virus-specific T-cell responses. Blood 2008;112(3):532-41.

79. Augello A, Tasso R, Negrini Simone M, et al. Bone marrow mesenchymal progenitor cells inhibit lymphocyte proliferation by activation of the programmed death 1 pathway. Eur J Immunol 2005;35(5):1482-90.

80. Corcione A, Benvenuto F, Ferretti E, et al. Human mesenchymal stem cells modulate B-cell functions. Blood 2006;107(1):367-72.

81. Kawashiri S, Tanaka A, Noguchi N, et al. Significance of stromal desmoplasia and myofibroblast appearance at the invasive front in squamous cell carcinoma of the oral cavity. Head Neck 2009;31(10):1346-53.

82. Lewis MP, Lygoe KA, Nystrom ML, et al. Tumour-derived TGF-beta1 modulates myofibroblast differentiation and promotes HGF/SF-dependent invasion of squamous carcinoma cells. Br J Cancer 2004;90(4):822-32.

83. Vered M, Dobriyan A, Dayan D, et al. Tumor-host histopathologic variables, stromal myofibroblasts and risk score, are significantly associated with recurrent disease in tongue cancer. Cancer Sci in press;101(1):274-80 [doi:10.1111/j.1349-7006.2009.01357].

84. Kojc N, Zidar N, Vodopivec B, Gale N. Expression of CD34, [alpha]-smooth muscle actin, and transforming growth factor [beta] 1 in squamous intraepithelial lesions and squamous cell carcinoma of the larynx and hypopharynx. Hum Pathol 2005;36(1):16-21.

85. Barth PJ, Schenck zu Schweinsberg T, Ramaswamy A, Moll R. CD34+ fibrocytes, alpha-smooth muscle antigen-positive myofibroblasts, and CD117 expression in the stroma of invasive squamous cell carcinomas of the oral cavity, pharynx, and larynx. Virchows Arch 2004;444(3):231-4

86. Ralhan R, Desouza LV, Matta A, et al. Discovery and verification of head-andneck cancer biomarkers by differential protein expression analysis using iTRAQ labeling, multidimensional liquid chromatography, and tandem mass spectrometry. Mol Cell Proteomics 2008;7(6):1162-73.
87. De Wever O, Pauwels P, De Craene B, et al. Molecular and pathological signatures of epithelial-mesenchymal transitions at the cancer invasion front. Histochem Cell Biol 2008;130(3):481-94.

88. Muehlberg FL, Song YH, Krohn A, et al. Tissue-resident stem cells promote breast cancer growth and metastasis. Carcinogenesis 2009;30(4):589-97.

89. Narine K, De Wever O, Van Valckenborgh D, et al. Growth factor modulation of fibroblast proliferation, differentiation, and invasion: implications for tissue valve engineering. Tissue Eng 2006;12(10):2707-16.

90. Liss C, Fekete MJ, Hasina R, Lam CD, Lingen MW. Paracrine angiogenic loop between head-and-neck squamous-cell carcinomas and macrophages. Int $J$ Cancer 2001;93(6):781-5.

91. Barcellos-Hoff M, Dix T. Redox-mediated activation of latent transforming growth factor-beta 1. Mol Endocrinol 1996;10(9):1077-83.

92. Mishra PJ, Mishra PJ, Humeniuk R, et al. Carcinoma-associated fibroblast-like differentiation of human mesenchymal stem cells. Cancer Res 2008;68(11):4331-9.

93. Menon LG, Picinich S, Koneru R, et al. Differential gene expression associated with migration of mesenchymal stem cells to conditioned medium from tumor cells or bone marrow cells. Stem Cells 2007;25(2):520-8.

94. Haniffa MA, Collin MP, Buckley CD, Dazzi F. Mesenchymal stem cells: the fibroblasts' new clothes? Haematologica 2009;94(2):258-63.

95. Knowles LM, Stabile LP, Egloff AM, et al. HGF and c-Met participate in paracrine tumorigenic pathways in head and neck squamous cell cancer. Clin Cancer Res 2009;15(11):3740-50.

96. Seiwert TY, Jagadeeswaran R, Faoro L, et al. The MET receptor tyrosine kinase is a potential novel therapeutic target for head and neck squamous cell carcinoma. Cancer Res 2009;69(7):3021-31.

97. Chiang W-F, Liu S-Y, Fang L-Y, et al. Overexpression of galectin-1 at the tumor invasion front is associated with poor prognosis in early-stage oral squamous cell carcinoma. Oral Oncol 2008;44(4):325-34.

98. Hwang JH, Shim SS, Seok OS, et al. Comparison of cytokine expression in mesenchymal stem cells from human placenta, cord blood, and bone marrow. J Korean Med Sci 2009;24(4):547-54.

99. Rehman AO, Wang CY. SDF-1alpha promotes invasion of head and neck squamous cell carcinoma by activating NF-kappaB. $J$ Biol Chem 2008;283(29):19888-94.

100. Chung $\mathrm{CH}$, Parker JS, Ely K, et al. Gene expression profiles identify epithelialto-mesenchymal transition and activation of nuclear factor-\{kappa\}B signaling as characteristics of a high-risk head and neck squamous cell carcinoma. Cancer Res 2006;66(16):8210-8.

101. Szczepanski MJ, Czystowska M, Szajnik M, et al. Triggering of toll-like receptor 4 expressed on human head and neck squamous cell carcinoma promotes tumor development and protects the tumor from immune attack. Cancer Res 2009;69(7):3105-13.

102. Midwood K, Sacre S, Piccinini AM, et al. Tenascin-C is an endogenous activator of toll-like receptor 4 that is essential for maintaining inflammation in arthritic joint disease. Nat Med 2009;15(7):774-80.

103. Zhang W, Matrisian LM, Holmbeck K, Vick CC, Rosenthal EL. Fibroblastderived MT1-MMP promotes tumor progression in vitro and in vivo. BMC Cancer 2006;6:52.

104. Sudo K, Kanno M, Miharada K, et al. Mesenchymal progenitors able to differentiate into osteogenic, chondrogenic, and/or adipogenic cells in vitro are present in most primary fibroblast-like cell populations. Stem Cells 2007;25(7):1610-7.

105. Studeny M, Marini FC, Dembinski JL, et al. Mesenchymal stem cells: potential precursors for tumor stroma and targeted-delivery vehicles for anticancer agents. J Natl Cancer Inst 2004;96(21):1593-603.

106. Jeon ES, Moon HJ, Lee MJ, et al. Cancer-derived lysophosphatidic acid stimulates differentiation of human mesenchymal stem cells to myofibroblast-like cells. Stem cells 2008;26(3):789-97.

107. Ball SG, Shuttleworth CA, Kielty CM. Platelet-derived growth factor receptoralpha is a key determinant of smooth muscle alpha-actin filaments in bone marrow-derived mesenchymal stem cells. Int $J$ Biochem Cell Biol 2007;39(2):379-91.

108. Jeon ES, Moon HJ, Lee MJ, et al. Sphingosylphosphorylcholine induces differentiation of human mesenchymal stem cells into smooth-muscle-like cells through a TGF-\{beta\}-dependent mechanism. J Cell Sci 2006;119(23):4994-5005.

109. Emura M, Ochiai A, Horino M, Arndt W, Kamino K, Hirohashi S. Development of myofibroblasts from human bone marrow mesenchymal stem cells cocultured with human colon carcinoma cells and TGF beta 1. In Vitro Cell Dev Biol Anim 2000;36(2):77-80.

110. Mareel M, Oliveira MJ, Madani I. Cancer invasion and metastasis: interacting ecosystems. Virchows Arch 2009;454(6):599-622. 